\title{
O ensino de técnica operatória na graduação e na residência médica
}

\section{Teaching surgical techniques during graduation and medical residence}

\author{
Marcelo A. F. Ribeiro Jr.
}

Professor Titular de Cirurgia Geral e Coordenador do Curso de Medicina da Universidade de Santo Amaro - UNISA Professor de Habilidades Cirúrgicas da Universidade Cidade de São Paulo - UNICID

palavra Técnica foi utilizada em medici-
na pela primeira vez por Hipócrates
[460 a.C.) e deriva do Grego TECNE = ARTE. Atualmente podem-se observar entre as 181 Escolas Médicas Brasileiras uma total falta de uniformidade no tocante ao ensino da Disciplina de técnica operatória durante a graduação assim como durante a residência médica. 0 bom exercício do ofício de cirurgião implica em amplo domínio técnico assim como amplo conhecimento teórico, alinhando com isto arte e ciência.

Entretanto, torna-se mister ressaltar que o ensino de tal disciplina ou matéria é fundamental não só do ponto de vista técnico, desenvolvimento de habilidades e estimulo a pesquisa, mas também sob o ponto de vista ético. Não é ético que alunos de graduação assim como Residentes de programas de Residência das diversas áreas cirúrgicas desenvolvam seu aprendizado prático utilizando o ser humano como ferramenta de aprendizado. Durante décadas o ensino da técnica operatória ficou a cargo de disciplinas geralmente pouco prestigiadas dentro das instituições, onde muitos docentes eram alocados muitas vezes sem a opção de escolha oriundos das diversas áreas cirúrgicas... Exceções à parte, como nos centros onde houve estimulo ao desenvolvimento de áreas de grande impacto como, por exemplo, a cirurgia cardíaca e os transplantes, a maioria dos serviços sempre foram tratados como um apêndice dos Departamentos de cirurgia.

Chama-nos a atenção a falta de regras e definições claras a respeito do ensino de tão importante disciplina para alunos não só da graduação como também para médicos residentes em fase de formação profissional. Sabe-se que se deve ensinar, entretanto não se conhece de forma clara o que, quando e como... Atualmente não há nem por parte dos órgãos reguladores, como por exemplo, MEC, nenhum tipo de recomendação especifica que legisle sob tal tema, nem tão pouco por parte da ABEM (Associação Brasileira de Ensino Médico) ou mesmo da SOBRADPEC (Sociedade Brasileira para o desenvolvimento da Pesquisa em Cirurgia], portanto cada escola acaba desenvolvendo seus programas onde, como e quando entender ser mais adequado.

Considerando agora não só o ensino como também a pesquisa, é fundamental o desenvolvimento ordenado de tal atividade, onde possa haver uma padronização e uniformização de conteúdo programático mínimo a ser aplicado, a fim de se minimizar as diferenças hoje observadas em todo o País. O problema adquire proporções alarmantes onde se tem a possibilidade de observar residentes do primeiro ano de cirurgia que nos primeiros meses de treinamento não apresentam habilidades técnicas mínimas, as quais deveriam ser desenvolvidas na graduação, visto não terem tido muitas vezes oportunidades adequadas de aprendizado.

Falta por tanto definição clara do tempo mínimo de ensino durante a graduação, a maioria das escolas ministram tal disciplina durante o $3^{\circ}$ ano do curso ou no 5ํㅡ e 6ํㅗ semestres, outras sob o argumento muitas vezes do custo, ministram o conteúdo em apenas um semestre. Modelos experimentais também são pouco padronizados, parte das vezes utilizando-se, por exemplo, porcos e em outros cenários coelhos e mesmo ratos da linhagem Wistar, cabe aqui a ressalva da 
importância da regra dos três R's proposta por Russell e Burch (1959) onde a definição dos modelos experimentais torna-se fator fundamental no ensino e pesquisa.

Quanto ao conteúdo teórico e prático não há nenhuma diretriz, fica a cargo de cada instituição a definição do conteúdo programático. Hoje se observam escolas aplicando o ensino, por exemplo, de técnicas micro cirúrgicas para todos os alunos, entretanto deixando de lado o ensino de manobras básicas em trauma por exemplo. Se formos analisar as diretrizes do MEC que tem como escopo formar médicos generalistas capacitados ao exercício profissional nos rincões deste imenso País, considero muito mais importante que um jovem profissional seja capacitado a realizar, por exemplo, uma drenagem torácica do que uma anastomose micro cirúrgica... Todavia é importante o contato assim como o manuseio de animais e tecidos vivos, onde o aluno possa vivenciar situações que simulem a atuação prática, portanto o manuseio de animais de experimentação sob condições éticas ainda é passo fundamental e insubstituível para o ensino. Obviamente a aplicação de ferramentas como simuladores virtuais, tecidos artificiais ou mesmo tecidos resfriados como a língua de boi, em muito agregam no desenvolvimento de raciocínio teórico-prático assim como de habilidades cognitivas.

0 ensino padronizado e bem definido da Técnica Operatória nas Escolas Médica deve de fato melhorar e deixar de ser encarado como algo pouco relevante, boa parte dos jovens estudantes, mesmo os que não têm interesse nas áreas cirúrgicas apreciam a oportunidade de estar realizando procedimentos práticos sob supervisão, cabendo aos Docentes o seu ensino ético e de qualidade, visto que o binômio Técnica Operatória e Cirurgia Experimental no meu entender indissociável, ira despertar o interesse pela pesquisa e busca do saber, trazendo estes jovens para dentro dos laboratórios desenvolvendo com isto a pesquisa.

Já na Residência Médica, segundo o programa oficial da Comissão Nacional de Residência Médica, é claramente definido que os residentes dos dois primeiros anos de Cirurgia Geral devem passar um mês dentre os 22 meses de treinamento na Técnica Operatória. Na prática como sabemos salvos parte dos programas desenvolvidos atrelados as Universidades, os demais, que se desenvolvem geralmente em Hospitais públicos Municipais e Estaduais ou mesmo Privados, não tem se quer laboratório de Cirurgia Experimental. Com isto o jovem que deveria adquirir refinamento de suas habilidades técnicas não tem como assim fazê-lo salvo realizado seu adestramento direto no ser humano, havendo, portanto uma infração ética grave, considerando-se que em primeiro lugar é prerrogativa básica não lesar ou agravar as lesões do próximo. Aqui cabe a discussão não só quanto ao tempo como a aplicação da lei. Um mês é pouco, um mês corrido é inadequado, portanto, quando? Como? E o que ensinar? Sugiro um programa contínuo e regular, com o laboratório sendo parte das atividades semanais dos Residentes. Programas de treinamento incluindo técnicas avançadas como princípios do controle de danos, bases técnicas de ressecções hepáticas, anastomoses vasculares e cirurgia minimamente invasiva devem ser treinadas e discutidas neste cenário. Mas muito antes disto devemos com apoio das entidades representativas como, por exemplo, o Colégio Brasileiro de Cirurgiões, fazer valer a lei vigente, a qual desafio que comprovem ser cumprida por todos os programas.

Diversos estudos internacionais demonstram que mesmo em centros de excelência o ensino formal dos residentes em laboratórios de treinamento especificamente com o escopo de desenvolverem as pressupostas habilidades especificas para atuarem em pacientes, atinge apenas 29\% dos programas pesquisados. (MANDEL et al.). Outros centros vem demonstrando que a utilização não só do laboratório de técnica como também as técnicas de realidade virtual oferecem uma maior segurança e melhora da performance destes médicos residentes no centro cirúrgico quando comparados a grupos não treinados. (SEYMOUR et al.).

O MEC e demais agencias reguladoras que determinam as leis vigentes na área, devem ouvir as sociedades de especialidade, realizar consultas e discutir, visto a falta de uniformidade no assunto.

Temos muito por fazer, mudanças, padronizações e definições de critérios e conteúdos, entretanto tenho a certeza de que a melhoria das condições de ensino e aprendizado de tão nobre disciplina ira de sobremaneira estimular não só os discentes como os docentes a se aprimorarem cada vez mais, e com isto formaremos médicos mais preparados e certamente junto virá a melhoria na produção cientifica assim como na qualidade da mesma em todos os centros do País. 


\section{Referências}

Russell WMS, Burch RL (1959) The principles of humane experimental technique. Methuen \& Co. Ltd., London.

Goldenberg S, Fagundes DJ. Inquerito Sobre O Ensino e A Pesquisa Em Técnica Operatoria e Cirurgia Experimental. Acta Cir Bras. 1986; 1:2-15.

Qayumi AK, Cheifetz RE, Forward AD, Baird RM, Litherland HK, Koetting SE. Teaching and evaluation of basic surgical techniques: The University of British Columbia Experience. J Invest Surg. 1999; 12:341-50.
Mandel LP, Lentz GM, Goff BA. Teaching and evaluationg surgical skills. Obstet Gynecol 2000; 95:783-5.

Seymour NE, Gallagher AG, Roman SA, O'Brien MK, Bansal VK, Andersen DK, Satava RM. Virtual reality training improves operating room performance: Results of a randomized, double-blinded study. Ann Surg. 2002; 236:458-64.

Rogers DA, Elstein as, Bordage G. Improving continuing medical education for surgical techniques: Applying the lessons learned in the first decade of minimal access surgery. Ann Surg. 2001; 233:159-66. 